\title{
ESTRATÉGIAS DE PRESERVAÇÃO PARA O PATRIMÔNIO CULTURAL
}

\section{PRESERVATION STRATEGIES FOR CULTURAL HERITAGE}

\author{
Sara Cura ${ }^{1}$ \\ Diogo da Silva Cardoso² \\ Luiz Antonio Pacheco Queiroz ${ }^{3}$ \\ Willian Carboni Viana 4 \\ Maria Clara Costa ${ }^{5}$
}

\begin{abstract}
RESUMO
As estratégias de preservação e conservação patrimonial têm lidado com conflitos de diversas ordens, segmentos e escalas. Sob este cenário complexo, o patrimônio cultural e, especificamente, sítios e bens arqueológicos, tornaram-se elementos centrais nos debates relacionados aos processos culturais, identitários, educativos, políticos e urbanísticos. 0 que tem atraído agentes de diferentes matizes políticas e econômicas, para satisfazer interesses que ora priorizam o lado estético do bem, ora reivindicam raízes históricas próprias. Neste sentido, a categoria patrimônio, como ferramenta analítica, será utilizada neste texto para embasar algumas considerações acerca dos bens arqueológicos e sobre as imbricadas práticas de preservação, conservação e valorização que favorecem a proteção da memória.
\end{abstract}

PALAVRAS-CHAVE: patrimônio arqueológico, preservação cultural, identidade, memória.

\section{ABSTRACT}

The strategies of preservation deal with different conflicts, segments and scales. It is under this complex scenario that cultural heritage and, in many cases, archaeological sites and artefacts, have become central elements in the debates of current cultural, identity, educational, political and urbanistic processes. Such a scenario attracts agents of different political and economic shades to satisfy interests that prioritize or the aesthetic side, or claim the Historical roots. In this sense, the heritage category as an analytical tool will be used in

\footnotetext{
${ }^{1}$ Doutora em Quaternário, Materiais e Culturas pela Universidade de Trás-os-Montes e Alto Douro (Portugal)

Instituto Terra e Memória e Centro de Geociências da Universidade de Coimbra

2 Doutor em Geografia pela Universidade Federal do Rio de Janeiro - UFRJ (Brasil)

Prefeitura Municipal de Santos, Professor Adjunto II

${ }^{3}$ Doutorando em Arqueologia no Departamento de Arqueologia da Universidade Federal de Sergipe - UFS (Brasil)

${ }^{4}$ Doutorando em Geografia no Departamento de Geografia da Faculdade de Letras da Universidade do Porto (Portugal)
}

${ }^{5}$ Mestre em História da Arte, Patrimônio e Cultura Visual pelo Departamento de Arqueologia da Faculdade de Letras da Universidade do Porto (Portugal)

\begin{tabular}{|l|l|l|l|l|l|l|}
\hline (C) Rev. Arqueologia Pública & Campinas, SP & v.13 & n.2 & p.63 & 2019 & ISSN 2237-8294
\end{tabular}


this text to base some considerations on the archaeological heritage and its preservation, conservation and valorization, which favour memory preservation.

KEYWORDS: archaelogical heritage, cultural preservation, indentity, memory.

\section{RESUMEN}

Las estrategias de preservación y conservación han abordado los conflictos de diferentes órdenes, segmentos y escalas. Bajo este complejo escenario el patrimonio cultural y, específicamente, los sitios y bienes en arqueología, se han convertido en elementos centrales en los debates sobre procesos culturales, educativos, políticos y urbanísticos. Lo qué atrae actores de diversas matices pilíticas y económicas, a satisfacer intereces que a veces priorizan el lado estético del bien, a veces reclaman raíces históricas propias. En esta dirección, la categoría de patrimonio como herramienta analitica, será utilizado para basar algunas consideraciones acerca de los bienes arqueologicos y las prácticas de preservación, conservación y valorización, que favorecen la protección de la memoria.

PALABRAS-CLAVE: patrimonio arqueologico, preservación cultural, identidad, memoria.

\section{INTRODUÇÃO}

O patrimônio arqueológico faz parte de um imenso grupo de valores coletivos, que atualmente se juntam sob a denominação geral de Patrimônio Cultural, compreendendo o Material e Imaterial. A ligação entre os elementos que o constituem é dada pela memória, uma vez que para um ou mais indivíduos, em uma comunidade, o patrimônio é carregado de significados reconhecíveis.

Neste mundo, muitas vezes imagético e imediatista que dita os ritmos da globalização e dos processos territoriais, o patrimônio cultural afronta à repetição de comportamentos acríticos, ao desgaste da memória social e ao empobrecimento cultural. $O$ patrimônio é materialidade crucial para a produção dos sentidos e dos significados para as sociedades do passado e do presente, mesmo que a sociedade contemporânea não conceba e/ou consiga transmitir plenamente a relevância das materialidades e imaterialidades patrimoniais para a memória e a identidade coletiva.

Há aqui um duplo desafio, semântico e epistêmico. Um campo fértil para agenciamentos culturais, sob os quais, até o momento, há mais perguntas do que respostas concretas sobre como dar um uso adequado ao patrimônio cultural, bem como incluí-lo na vida social com poucas restrições. Deste modo, sítios arqueológicos são locais resistentes aos desgastes do tempo, representam espaços de memória coletiva que conduzem à outras 
épocas, nas quais ocorreram os feixes de relações entre humanos e materiais diversos, e entre pessoas (JORGE, 2003B). São também lugares de redutos, individuais ou coletivas, que conservam e ampliam valores de elementos atemporais, em meio a um mundo em rápida alienação e em risco de entropias várias.

A valorização do patrimônio arqueológico implica, sobretudo, em escolher entre os muitos discursos e agenciamentos relacionados ao local. Desde os enunciados científicos às memórias locais, tudo contribui para a apropriação de um sítio patrimonial, práticas de pertencimento, presença e sentido. Consequentemente, boas práticas geram um alargamento da rede social na qual o sítio se integra (OOSTERBEEK, 2003, p. 351).

No que diz respeito ao saldo de sítios destruídos, ficam os vestígios materiais recuperados nos trabalhos de minimização de impacto. Materiais que se vão acumulando nas reservas, em melhores ou piores condições, sem que haja um estudo detalhado que se poderia traduzir num discurso de valorização, por conseguinte com grande potencial educativo e identitário. Ainda que o conhecimento da diversidade da experiência humana seja propiciado na etapa de resgate.

Portanto, sítios arqueológicos constituem um patrimônio frágil e vulnerável, do qual, hoje, só se pode recorrer a uma parte mínima da completude inicial e, por isso, merecem todas as ações possíveis de organizações públicas, associativas ou privadas, para que se possa assegurar a preservação destes locais de interesse cultural coletivo (COLLADO GIRALDO et al., 2014). A perspectiva de que o estudo dos vestígios materiais permite acessar informações únicas do passado, leva a propor a preservação e a valorização dos bens arqueológicos, entendidos como lugares que guardam e ressoam experiências, visto que ao longo da trajetória, histórica e milenar, os humanos tiveram um papel integrante, participativo, modificador e formador das paisagens que habitaram.

Contudo, como valorizar o acampamento de um grupo caçador-coletor sem explicar o nomadismo e, por consequência, toda a extensa paisagem com a qual interagia? Há aqui um preservar e valorizar do sítio em si que não pode ser modificado via proteção legal, mas que trata da valorização de uma paisagem, passando por um discurso, uma narrativa dos modos de vida e eventos passados, refletidos no arranjo espacial do que é considerado sítio arqueológico. 
Há que se pensar e agir para a promoção de um saber arqueológico e cultural crítico, que, simultaneamente, indague e explique para distintos públicos a importância dos vestígios culturais de um determinado bem arqueológico, o que implica em trabalho prévio de seleção de informação, mediação e transmissão. E, neste sentido, se definir o circuito pela qual a comunicação será efetivada, a levar-se em conta questões como: a socialização do conhecimento científico, ludicidade, metodologias ativas, despertamento de curiosidade, representações simbólicas e artísticas, entre outras.

\section{DIMENSÕES DA VALORIZAÇÃO DO PATRIMÔNIO}

No processo de comunicação, a escolha de como tratar a informação tem, no conceito vygotskyano de mediação, um ganho para inclusão e interação com os indivíduos que, espera-se, estejam engajados na atribuição de valor ao patrimônio arqueológico. Acionada para facilitar iniciativas de socialização do conhecimento, a mediação permite a atuação de ambos, comunicador e espectador/participante, numa tomada de consciência em descobertas do que está ali armazenado, assimilado e transformado em tradição pela comunidade local e outros agentes envolvidos. Na contemporaneidade, a valorização/ conservação tem pressuposto a criação de todo um sistema que não faça do visitante alguém passivo, mas ativo e participante.

Isto não quer dizer que tudo seja uma dinâmica de comunicação, também deve haver espaço para a contemplação e reflexão. No processo de divulgação dos saberes, fazeres e bens que contextualizam o sítio arqueológico, há que se discutir o que vem a ser, de fato, o sítio arqueológico.

Vítor de Oliveira Jorge fornece uma definição interessante, para se pensar a valorização enquanto ação cultural estratégica à sustentabilidade do patrimônio:

\footnotetext{
Um sítio arqueológico é um acumulador de valores: tem a ver com memória; com o colectivo; com o transporte para outros tempos; com a observação directa do que resistiu à erosão e portanto deixa entrever a eternidade; com a melancolia da perda, e a religiosa 'lição' de que mesmo os grandes, os que viveram de forma opulenta, terminam em pó e os seus palácios em ruínas; de que afinal as ervas e os bichos tomam conta de tudo, se não se cuida das ruínas todos os dias, assim como se esvaziam os contentores de lixo, ou se limpam os sanitários (JORGE, 2003B, p. 162).
} 
Há que explicar o colapso. Há que cuidar sempre. Ao arqueólogo e demais estudiosos envolvidos na arqueologia, não basta escavar, estudar os vestígios e publicar dentro da academia. A socialização do conhecimento de forma irrestrita é o que interessa, para não levar os repositórios acadêmicos a tornarem-se depósitos de informações inatingíveis ao grande público, e por isso dados como irrelevantes pela população em geral.

Hoje, o pesquisador em Arqueologia tem que pensar no papel do sítio em que está a trabalhar, para que a fruição possa se estender a vários grupos sociais e, dessa forma, dissolver-se o elitismo que, tradicionalmente, molda as relações entre os agentes que atuam nesse campo. É um caminho de descolonização que precisa ser galgado com o envolvimento de todos, em que as menções das heranças culturais não pode ser apenas àquelas que aludem ao passado de heróis criados pelas lentes ofuscantes da história oficial culpada pela marginalização das pessoas de baixo.

Portanto, esta ação valorativa necessita de uma decisão anterior, sobre os públicos a que se pretendem atingir, devendo ser construída, sob pena de ser inútil na relação com as pessoas inseridas no processo. Mas, a valorização tem um sentido de peso, para além da população local, nos públicos que se deslocam no território e, por isso, só pode ser eficaz quando inserida numa estratégia territorial (OOSTERBEEK, 2003). Isto é, o vetor da valorização tem um destinatário direto, o seu potencial público, o que não quer dizer que se deva desvalorizar outras tarefas, como, por exemplo, o estudo, a preservação e a manutenção dos sítios (MATOS, 2008).

A escolha dos sítios a valorizar "não pode estar dependente de pressões sociais, juízos estéticos, conciliação de interesses, de questões técnicas ou da singularidade dos vestígios" (MATOS, 2008, p. 34). Assim, sendo aceite e lógico que o fundamento da pesquisa arqueológica é o aumento do conhecimento do passado, um problema complexo se coloca quando se trata de se escolherem e justificarem outros usos para os sítios pesquisados (TELLER; WARNOTTE, 2003).

A valorização tem outro problema: é onerosa. Uma boa valorização tem múltiplos discursos preparados para os diversos tipos de público, acessos ao sítio em condições de trafegabilidade, estruturas de proteção, reconstituições (em maquetes, desenhos ou em dispositivos multimídia), painéis e placas interpretativas indicando o percurso de visita, pelo 
menos um centro interpretativo de acolhimento, de exposição de objetos exumados e com espaço para as projeções digitais.

Uma boa proposta de valorização é tarefa difícil, complexa, pois tem de corresponder à fruição dos mais diversos públicos, diferentes faixas etárias e graus de conhecimento. O discurso tem de ser acessível, mas rigoroso. Jacques Teller e Anne Warnotte apontam uma concepção a respeito do papel de um sítio, pós-escavação e pósinvestigação:

\begin{abstract}
A valorização de um sítio arqueológico é distinta das outras formas de popularização, já que ela convida o público para aquilo que é, ou que foi, um laboratório de investigação. É claro que isto apresenta benefícios e, também, desvantagens. Os benefícios mais significativos são, sem dúvida alguma, o contacto directo entre o visitante e a evidência tangível do passado, bem como a possibilidade da sua participação no progresso da investigação. Entre as desvantagens, está o facto de uma escavação ser, por definição, um processo destrutivo. É necessário, portanto, prever-se a valorização futura durante o decurso das investigações arqueológicas, num tempo em que a natureza total das descobertas ainda não é conhecida (TELLER; WARNOTTTE, 2003, p. 4).
\end{abstract}

Tudo isto exige uma preparação rigorosa e muito bem pensada, multidisciplinar, interdisciplinar e colaborativa. Atualmente, os arqueólogos, educadores patrimoniais e outros agentes interessados têm uma função educacional e social importantíssima, é lhes exigido grande trabalho para conceber a valorização de um sítio. Nesse sentido, o agente do patrimônio é relevante na medida em que suas decisões dependam:

[...] da sua capacidade para encontrarem o delicado equilíbrio entre a execução de uma cientificamente elevada investigação - sem a qual todas as obras de valorização são espúrias, a preservação dos vestígios arqueológicos para as gerações futuras, e a selecção dos vestígios que devem ser retidos para finalidades educativas, o que possibilitará aos futuros visitantes compreenderem a evolução do sítio (TELLER; WARNOTTTE, 2003, p. 4).

A preservação do sítio e da paisagem circundante vai ao encontro das declarações da UNESCO, expressadas em 1972 na Convenção sobre a proteção do Patrimônio, Mundial, Cultural e Natural. O que incide na necessidade de o transmitir às gerações futuras em simultâneo o patrimônio cultural e natural, conceito que se fortalece com o desenvolvimento do termo Paisagem Cultural (COLLADO GIRALDO et al., 2014). 


\section{POLÍTICA DE SELEÇÃO DO PATRIMÔNIO A VALORIZAR}

Um bem arqueológico não só possui significados culturais e históricos, também carrega consigo valores ecológicos e paisagísticos. Depois de Donald Meinig (2002), os cientistas e técnicos do patrimônio podem se nutrir da perspectiva de que a paisagem, e o acervo patrimonial territorializado a esta pertencente, pode ser apresentada de diferentes formas, dependendo dos ângulos visual, ideológico e prático. Tanto no âmbito da prática arqueológica, quanto no campo institucional patrimonial, procedimentos conceituais e metodológicos são primordiais nas decisões da preservação e da valorização.

No entanto, as atitudes para a preservação, conservação e valorização precisam ser direcionadas através das estratégias que encerram a atenção em comunidades locais, e, por conseguinte, avancem para além das metanarrativas e discussões patrimoniais do contexto mundial (RIBEIRO, 2007, p. 10 e 11). Tal visão é essencial para substanciar a identidade humana com decisões que abarquem, de forma inclusiva e democrática, a população. Sempre com o objetivo de aproveitar as sinergias que possam resultar desta interação, mantendo os requerimentos dos efeitos de proteção legal, preservação e difusão (COLLADO GIRALDO et al., 2014).

Dessa forma, os vestígios materiais e a história de povos dominados, marginalizados, esquecidos, negligenciados pela história dita oficial, podem ser alçados à categoria de patrimônio, num rumo contrário às práticas elitistas e colonizadoras (FUNARI; PELEGRINI, 2006, p. 26 e 27). Assim, as proposições para a seleção do que preservar ganham contornos em critérios de relevância cultural e científica, fundamentos que no ocidente têm sido apreendidos com base nas narrativas e na memória social:

A memória é o mecanismo de permanente (re) organização do Passado. É ela que coloca os "vestígios do passado" em relação uns com os outros, conferindo-lhes sentido. Dito de outra forma, é ela que, jogando com um conjunto de elementos materiais isolados (que podem ser impulsos eléctricos ou unidades de matéria, mas que, no plano colectivo, são também ruínas, sepulturas, pontes ou palácios), constrói uma dimensão coerente, a que damos o nome de passado, ou de Património Cultural e que, em última análise é de natureza imaterial (OOSTERBEEK, 2004, p. 44).

Mecanismo este que se situa, na prática patrimonial, enquanto maneira de conscientização histórica, expressa na paisagem cultural, concebida através da identidade 
profundamente associada ao controle dos bens patrimoniais pelo estado nacional (LYDON, 2008, p. 655-657). A disseminação desta concepção é arraigada em estratégias de identificação e preservação, que se estenderam mundialmente a partir da UNESCO nas últimas décadas do século XX. A ideia de paisagem cultural seguiu as discussões em diversas disciplinas, que ampliaram a visão da paisagem, não mais admitida como uma noção apenas relativa às características do meio físico, mas, e principalmente, com referência a partir do papel ativo dos sujeitos sociais (COSGROVE, 1998, p. 11; KNAPP; ASHMORE, 1999, p. 3; THOMAS, 2001, p. 170 e 171).

A recorrência da paisagem cultural como recurso das ações, que alçam lugares à categoria de patrimônio cultural, trata-se de algo recente no Brasil. Para Rafael Ribeiro:

[...] existe ainda um longo caminho de reflexão a ser percorrido, para que se possa tornar a ideia de paisagem cultural uma categoria operacional nas instituições de preservação do patrimônio cultural brasileiro (RIBEIRO, 2007, p. 9).

Por isso, uma tarefa fundamental é o entendimento que o bem arqueológico apresenta recursos finitos, e que sua deterioração pode conduzir ao seu desaparecimento. A má gestão do local, o vandalismo e a pressão urbanística envolvente são exemplos de fatores negativos e perturbadores de um espaço desta natureza (OLIVEIRA, 2013).

Aqui, a valorização assume papel fulcral na medida em que a sensibilização da população, em relação ao patrimônio a que se insere, torna-se aliada da preservação. É necessário refletir sobre a apresentação, modelando a preservação integrada e dimensionando estratégias que permitam a efetiva compreensão, por parte do público alvo, das mensagens do passado e do presente - a assegurar uma gestão sustentável. Trata-se, deste modo, de superar o fosso entre o patrimônio e os que usam o patrimônio, numa lógica que estimule a construção de conhecimento, a disseminação, a qualidade das experiências do usufruto e, igualmente importante, a longevidade do patrimônio arqueológico (MBWAMBO; OOSTERBEEK, 2015).

A prática aberta da arqueologia, em usar referenciais de outras disciplinas, compõem caminhos eficazes para a preservação, como, por exemplo, quando se utiliza a visão relacional comum ao campo da museologia (MORAES-WICHER, 2010, p. 36). Por certo, a arqueologia possui inegável relevância no seio das Ciências Humanas. Por um 
lado, a Arqueologia traz a capacidade de explicar mecanismos de adaptação, equilíbrios entre economia e ambiente, entre técnicas e tecnologia, por outro, oferece inúmeras possibilidades de abordagens multidisciplinares e interdisciplinares. Quando trata dos tópicos mencionados, favorece compreensões das relações entre recursos e necessidades, técnicas e energias, bem como entre conhecimento e território:

\begin{abstract}
Archaeological research offers to contemporary society, hence, an integrated insight into past landscapes and their human dynamics, contributing to disseminate awareness of adaptation mechanisms and of the need to value all levels of information. It is this insight that calls for a specific type of reasoning that proves to be useful in contemporary society and, we believe, it is in this line that heritage management can be useful for fostering a dynamic of cultural integrated landscape management (MBWAMBO; OOSTERBEEK, 2015, p. 49).
\end{abstract}

Neste sentido, comumente afirmam-se que os processos de identificação e caracterização dos sítios arqueológicos são tratados dentro da atribuição de valor, um valor que deve ser certificado em termos de qualidade (OOSTERBEEK, 2010). Não obstante, existem direcionamentos que exigem avanços no tratamento da informação a ser divulgada, que então conferem proposições de disseminação social do entendimento desses lugares como marcas de vida.

Em um primeiro momento, a valorização deve ser feita com a população local, pois a comunidade toma consciência do valor do seu patrimônio, da sua história e identidade, estando próximos dos sítios com maior eficácia, vai evitar a sua degradação (ideia de multiplicadores). Providenciar uma compreensão dos humanos como uma ponte envolvendo a sociedade (organizações), ambiente (contexto) e economia (comportamento), permite o entendimento dos significados dos sítios como conjuntos especializados, para uma gestão integrada da paisagem ancorada no desenvolvimento sustentável (MBWAMBO; OOSTERBEEK, 2015).

Esta premissa tem raízes na expansão do conceito de Patrimônio Cultural, o que inclui todas as evidências passadas, sendo atribuído valor pelas sociedades contemporâneas. Tal fato demonstra a necessidade de reconhecer, no patrimônio, os interesses dos diversos agentes envolvidos (população, poder local, regional e nacional, organizações privadas) que frequentemente estão em conflito, dado que possuem naturezas diversas. 
A esse trabalho também se pode dar o nome de Educação Patrimonial, com papel crucial no processo de conscientização e sensibilização social do potencial e da fragilidade do patrimônio, num mundo em constante mutação das suas formas materiais e sociabilísticas. Ao ensinar a todas as faixas etárias, sobretudo crianças e adolescentes, tenta-se garantir a futura preservação e valorização do patrimônio arqueológico, pois as pessoas conscientizadas podem assumir o patrimônio como seu, como fator estruturante da sua identidade. No mesmo diapasão, Carlos Azevedo Netto afirma:

\begin{abstract}
Nesta relação entre os sítios arqueológicos (não importando a cronologia), a cultura material (in situ ou recuperada) e as comunidades que habitam nas proximidades deve ser vista como um desdobramento de experiências próximas e distantes (Geertz, 1993), de modo concomitante, já que se trata de uma proximidade pelo espaço compartilhado e uma distância do marco cultural entre o produtor do registro arqueológico e o espectador atual. Essa proximidade e a barreira do distanciamento é que tem sido investida das formas de educação patrimonial, na sua maioria por imposição legal (Portaria 230 do Iphan) como estratégia de preservação, com o intuito de conscientização dos grupos de entorno dos bens arqueológicos, mas sempre com a premissa de formar espectadores desse patrimônio (AZEVEDO NETTO, 2008, p. 15).
\end{abstract}

Na relação, criada por ações educativas que permeiam a Educação Ambiental como um desdobramento da Educação Patrimonial, quando se pensando no ambiente como um todo, formam laços de pertencimento e condições de proteção e dinamização do patrimônio, postas efetivamente em ação pelos atores locais (poder público, moradores, profissionais, empresas etc.). A Educação Ambiental não remete a esquecer de como a questão ecológica e a sustentabilidade devem estar inseridas na agenda de discussões dos agentes do patrimônio.

Então, o que preservar e valorizar? O que pôr em oposição? O que não preservar e valorizar? São questões extremamente complexas! Por vontade, todo e qualquer vestígio de ocupação humana do passado. Por meio dos dispositivos classificatórios, muitos sítios e artefatos arqueológicos estão protegidos, mas desses só uma ínfima parte estão, de fato, protegidos e valorizados enquanto tais. Infelizmente, a destruição torna-se a regra, e não exceção, em muitos sítios brasileiros.

A identificação de diversos valores e significados possibilita determinar uma fruição e uma gestão equilibrada em diferentes âmbitos: científico, identitário, turístico/recreativo e econômico, todos sob o esteio da gestão integrada do território. Estes são conceitos e 
práticas que haveria de estar presentes em todas as políticas públicas relacionadas ao patrimônio, bem como nos planos urbanísticos e de revitalização espacial.

\section{PATRIMÔNIO ARQUEOLÓGICO: ENTRE MEMÓRIAS E IDENTIDADES}

A memória é a possibilidade consciente de se colocar na linha do tempo, de se viver com passado, presente e futuro. Assim, a memória trata da capacidade que uma sociedade tem de se rever em experiências anteriores (representações e construções mentais?!), o que Ihes possibilita de saber quem são:

Tanto o património (cujo contraponto poderia ser a poluição, ou o lixo, que tanto ameaça o mundo moderno - ou melhor: é um dos seus elementos estruturalmente constituintes) como a identidade (também com o seu contraponto, a alteridade) só têm sentido do ponto de vista "interno", dos sujeitos (individuais ou colectivos) que, com a sua experiência, cosmovisão, cultura, qualificam desta ou daquela maneira, classificam deste ou daquele modo, inserem tudo numa escala de valores e num quadro de referências, numa cartografia de qualidades e afectos que orienta os nossos trajectos de vida (JORGE, 2003A, p. 57).

Por isso, um dos motivos, se tem dado conta de que é necessário preservar e valorizar o patrimônio arqueológico, aquele bem que nos conta algo relacionado ao que se passou. Porém, esta atitude não deve ser entendida como conservadora, nostálgica, mas como forma de resistência dinâmica para que, futuramente, novas gerações tenham com o que se identificar no passado, e possam dele usufruir de forma sustentável a partir de alguns paradigmas que emergem e que orientam, atualmente, boa parte da política patrimonial, como, a ocupação de prédios históricos ociosos, a educação patrimonial, a economia criativa e a produção artesanal.

No esteio do patrimônio arqueológico, os especialistas que lidam diariamente com essa modalidade de bem cultural não podem deixar de lado que:

Fazer arqueologia não pode, hoje, ser uma pura prática museológica, ou universitária, ou patrimonial, ou empresarial, ou de investigação, ou de docência, ou de gestão, ou de intervenção de emergência. Deve ser tudo isso, mas também, quando, onde, e sempre que possível, uma meta-atitude de raciocínio reflexivo sobre o que andamos a fazer (JORGE, 2003B, p. 170). 
E ainda:

\begin{abstract}
E se a história nos indica exemplos e tendências que ainda marcam o presente, a arqueologia reconstrói o passado a partir de materialidades, e destaca sobretudo as condições naturais e tecnológicas das dinâmicas sociais. Por isso, o lugar da arqueologia na sociedade do século XXI não se limitará à muito importante função de contribuir para perspectivar o passado, mas cada vez mais consistirá na compreensão e valorização da tecnologia e da gestão dos recursos no território (OOSTERBEEK, 2013, p. $32)$.
\end{abstract}

Um dos lugares comuns do patrimônio arqueológico é a tentativa da fixação de algo que, desde sempre, foi dinâmico, sinérgico, produzido na contingência dos eventos e estruturas socioespaciais. Os objetos e ruínas foram processos de vidas e eventos pósdeposicionais, um acúmulo de memórias (CANDAU, 2011), conjunto de formas materiais (SANTOS, 1994) que coexistem com as atuais e emergentes temporalidades e configurações sociotécnicas. Logo, contemporâneas.

Para Doreen Massey (2008), a coexistência de trajetórias e temporalidades humanas e não humanas é condição para a existência do próprio espaço geográfico. Sem a existência de geografias pretéritas, o lugar não se efetiva como espaço de presença e de produção de sentido. Não há temporalidade-materialidade em desuso ou que não tenham o direito de sobreviver na paisagem. Aderir a este discurso é cair no preconceito, na narrativa anacrônica e colonizadora denunciada por Johannes Fabian (2013), que estabeleceu como dominante tanto a cosmovisão modernista, como as práticas de acumulação ad infinitum da economia capitalista.

Refletir sobre as perspectivas que levam à preservação do patrimônio é também assumir sua significância histórica. Reforça a característica, de âmbito mundial, tanto nas dinâmicas culturais que se inserem com suas feições vinculadas ao tempo em que são produzidas, quanto às tendências mais pujantes de preservação patrimonial - relativas à identidade nacional (CHUVA, 2012).

No entanto, as discussões sobre o que preservar tiveram diferentes momentos históricos, tendo o patrimônio a ser preservado várias atribuições de valor, e aqui destacamse a consolidação dos estados nacionais em formação, ou em regimes opressivos, estando a decisão do que e de como preservar a cargo de grupos ideológicos de poder, que ○() Rev. Arqueologia Pública Campinas, SP \begin{tabular}{l|l|l}
$\mathrm{v} .13$ & $\mathrm{n} .2$
\end{tabular} p.74 2019 ISSN 2237-8294 
selecionavam e interpretavam o patrimônio. Em ambos os casos acima citados, o patrimônio foi utilizado como uma arma política de propaganda, para legitimação do poder pelo grupo social dominante.

$\mathrm{Na}$ origem da seleção do que preservar está também a exploração econômica do passado pelo turismo, como, por exemplo, no caso do Egito, que tende a preservar as pirâmides e demais monumentos associados, negligenciando outros bens relacionados à história do país, com o objetivo de garantir o fluxo turístico de massas. Por outro lado, a preservação do patrimônio arqueológico também é feita por comunidades que procuram a sua significação, para demarcar a sua etnia e território, é o caso, por exemplo, dos aborígenes australianos e dos indígenas sul-americanos.

\section{CONSIDERAÇÕES FINAIS}

A monumentalidade e a visibilidade, por mais atrativas e importantes que sejam na era do capitalismo cognitivo e da economia criativa, nem sempre correspondem ao valor científico que o sítio ou o bem arqueológico deveria expor. Evidentemente há sítios de grande importância que tem pouca visibilidade, neste caso, deve ser a valorização a complementar a visibilidade, instalando os mais diversos dispositivos que expliquem o valor e unicidade do patrimônio em questão.

O Patrimônio Cultural é uma esfera de rebatimento das condições sóciohistóricas locais. Rebatimento este que ocorre diante de acontecimentos, dinamismos e decisões que a sociedade toma em relação a proteção e usufruto dos bens. Desde os naturais aos artefatos arqueológicos, os testemunhos materiais e imateriais do passado são alvos constantes de questionamento e de ressignificação, espiralando pela vida social e seguindo o fluxo tanto dos agentes autorizados - dos que falam em nome do patrimônio, como daqueles que almejam dar outras finalidades aos objetos e ao espaço patrimonializado.

Organizar, valorizar, gerir e comunicar envolve estratégias meticulosas, que põem a sociedade em contato e movimento com as características do sítio. A gestão do patrimônio arqueológico requer sinergias entre poder público, sociedade civil e agentes culturais, para desmistificar o processo de comunicação e estreitar o laço entre os stakeholders. Nesse 
sentido a mediação nas tarefas de educação voltadas ao patrimônio, segundo parâmetros da socialização dos intricados significados dos materiais arqueológicos, é fundamental para a disseminação de forma ampla e para fazer chegar ao cotidiano de todas as pessoas as informações de suas heranças culturais.

A desafiante prática de tornar acessível o conhecimento produzido deve ser antecedida de tomadas de decisões adequadas, para dar oportunidade a todos que desejam criar e transmitir a própria construção do passado. Um movimento que conduz a uma experiência de afirmação do outro, esse outro do passado que persiste no tempo presente. Como um resíduo que se recicla e se ressignifica, o patrimônio arqueológico deve ser tomado em toda a sua radicalidade e singularidade, em constante mutação e repleto de lacunas epistêmicas, sociais e geracionais.

\section{REFERÊNCIAS}

AZEVEDO NETTO, Carlos Xavier. Preservação do patrimônio arqueológico: reflexões através do registro e transferência da informação. Ciência da Informação. v. 37, n. 3, set./dez. p. 7-17, Brasília. 2008. Disponível em:

<http://www.scielo.br/pdf/ci/v37n3/v37n3a01.pdf>. Acesso em: 9 ago. 2017.

CANDAU, Jöel. Memória e identidade. São Paulo: Contexto, 2011. 219 p.

COLLADO GIRALDO, H., REY GARCÍA, J. M.; OOSTERBEECK, L. Hacia una nueva candidatura mundial: "Paisajes simbólicos del occidente peninsular. El arte rupestre esquemático como unidad cultural". Cuadernos de Arte Rupestre. n. 7, p. 263-27, 2014. Disponível em: <http://www.cuadernosdearterupestre.es/arterupestre/7/Articulo15.pdf>. Acesso em: 5 ago. 2017.

CHUVA, Márcia. Por uma história da noção de patrimônio cultural no Brasil. Revista do Patrimônio Histórico e Artístico Nacional. n. 34, p. 147-165, 2012. Disponível em: $<$ https://goo.gl/f4bfxt>. Acesso em: 05 ago. 2017.

COSGROVE, Denis Edmund. Social Formation and Symbolic Landscape. Winsconsin: University of Wisconsin Press, 1998.

FABIAN, Johannes. O tempo e o outro: como a antropologia estabelece seu objeto. Petrópolis: Vozes, 2013.

FUNARI, Pedro Paulo, PELEGRINI, Sandra de Cássia Araújo. Patrimônio Histórico e Cultural. Rio de Janeiro: Jorge Zahar Editor, 2006.

IPHAN. Educação Patrimonial: Histórico, conceitos e processos. Brasília: Instituto do Patrimônio Histórico e Artístico Nacional, 2014. Disponível em: <https://goo.gl/n2dLtY>. Acesso em: 20 jul. 2017.

\begin{tabular}{|l|l|l|l|l|l|l|}
\hline (C) Rev. Arqueologia Pública & Campinas, SP & v.13 & n.2 & p.76 & 2019 & ISSN 2237-8294
\end{tabular}


JORGE, Vitor Oliveira. A Irrequietude das Pedras: reflexões e experiências de um arqueólogo. Porto: Edições Afrontamento, 2003A.

Olhar o Mundo como arqueólogo. Coimbra: Quarteto, 2003B.

KNAPP, Bernard, ASHMORE, Wendy. Archaeological landscape: constructed, conceptualized, ideational. In: ASHMORE, Wendy; KNAP, Bernard. (Ed.) Archaeologies of Landscape: contemporary perspectives. Massachusetts/Oxford: Blackwell Publishers, 1999. p. 1-32.

LYDON, Jane. Contested Landscapes - rights to history, rights to place: Who controls archaeological places? In: DAVID, Bruno, THOMAS, Julian (Ed.) Handbook of Landscape Archaeology. Canada: Left Coast Press, 2008. p. 654-660.

MASSEY, Doreen. Pelo espaço: uma nova política da espacialidade. Rio de Janeiro: Bertrand Brasil, 2008.

MATOS, Olga. Valorização de sítios arqueológicos. Praxis ARCHAEOLOGICA. n. 3, Porto, p. 31-46, 2008. Disponível em: <https://goo.gl/BWVfxH>. Acesso em: 8 ago. 2017.

MBWAMBO, Everline E., OOSTERBEEK, Luiz, Rethinking the presentation at Olduvai Gorge site museum within Integrated Landscape Management (ILM) framework, Africana Studia, Revista Internacional de Estudos Africanos. n. 24, p.57-64, 2015.

MEINIG, Donald. O olho que observa: dez versões da mesma cena. Espaço \& Cultura. $n$. 13, jan./jun. p. 35-46, 2002. Disponível em: <https://goo.gl/V5mUnQ>. Acesso em: 10 nov. 2014.

MORAES-WICHERS, Camila de Azevedo. Museu e Antropofagia do Patrimônio Arqueológico: (des) caminhos da prática brasileira. Lisboa: Universidade Lusófona de Humanidades e Tecnologias. Tese de Doutoramento em Museologia, 2010.

OOSTERBEEK, Luiz. Da investigação à cenografia. Construções de meta realidades. 2003. Disponível em: <https://goo.gl/xkfydB>.

Arqueologia Pré-Histórica: entre a cultura material e o património intangível.

Cadernos do LEPAARQ - Textos de Antropologia, Arqueologia e Património. v. 1, n. 2, p. 41-54, Pelotas: EdUFPEL, 2004. Disponível em: <https://goo.gl/qmdwXS>. Acesso em: 8 ago. 2017.

Dominant vs. undermined values? A perspective from the most western seaboard of Europe. Measuring the value of material Cultural Heritage. n. 2, p. 46-53. Roma: DRI/ Fondazione Enotria/ ONLUS, 2010.

Looking at a global disruption in three steps, plus one to overcome it. Territori della Cultura. n. 8, p. 14-21, 2012. Disponível em: <https://goo.gl/jo6kCq >. Acesso em: 2 ago. 2017.

Do património ao território: um novo contexto para a arqueologia. ARKEOS. $n$. 34, p. 23-32, 2013. Disponível em: <https://goo.gl/ZwxKQA >. Acesso em: 2 ago. 2017. 
OLIVEIRA, Daniel Felipe da Costa. Valorização e Conservação de Sítios Arqueológicos: Oportunidade de recriação de cenários remotos. "Parc de la Pré-Histoirede Casablanca". Dissertação de Mestrado. Departamento de Geociências, Ambiente e Ordenamento do Território, Universidade do Porto, 2013. Disponível em: <https://goo.gl/GUjaTZ>.

RIBEIRO, Rafael Winter. Paisagem cultural e patrimônio. Rio de Janeiro: Iphan/Copedoc, 2007.

SANTOS, Milton. Metamorfoses do espaço habitado. São Paulo: Hucitec, 1994.

TELLER, Jacques; WARNOTTE, Anne. A valorização dos vestígios arqueológicos num contexto urbano. In: APPEAR Position Paper, n. 1, nov., p. 1-6, 2003. Disponível em: <https://goo.gl/GedZQC>. Acesso em: 5 ago. 2017.

THOMAS, Julian. Archaeologies of place and landscape. In: HODDER, lan (Ed.).

Archaeological Theory Today. New Jersey: Blackwell Publishers, 2001. p. 165-186.

Recebido em: 23/10/2019

Publicado em: 15/02/2020 